Ensino, Saúde e Ambiente - V7 (2), p. 28-45, Ago. 2014

\title{
EDUCAÇÃO AMBIENTAL: CONSTRUINDO CONHECIMENTOS SOBRE A PROBLEMÁTICA DOS AGROTÓXICOS
}

\section{ENVIRONMENTAL EDUCATION: BUILDING KNOWLEDGE ABOUT THE PROBLEM OF PESTICIDES}

\author{
${ }^{1}$ Ivanilda de Sousa Ferreira, ${ }^{1}$ Adriana Maria Antunes \\ ${ }^{1}$ Especialização em Tecnologias Aplicadas ao Ensino de Biologia, Instituto de Ciências Biológicas IV, \\ Universidade Federal de Goiás (ETAEB-ICB-UFG), Campus II, Goiânia, Goiás, Brasil. \\ ivanilda_68pls@hotmail.com adrianaantunesbio@gmail.com
}

\begin{abstract}
RESUMO
A Educação Ambiental (EA) visa sensibilizar os cidadãos para os problemas ambientais e para a preservação do meio ambiente. Assim, o presente trabalho teve como objetivos elaborar, aplicar e avaliar a eficácia do vídeo intitulado "Educação Ambiental: construindo conhecimentos sobre a problemática dos agrotóxicos" como tecnologia educacional para abordar o consumo indiscriminado dos agrotóxicos e suas consequências ao ser humano e ao meio ambiente. O vídeo foi elaborado através do programa editor de vídeos Windons MovieMaker ${ }^{\circledR}$, instalado no sistema operacional Windons XP®, e exibido para os alunos do $4^{\circ}$ Ano de Ensino Médio da Educação de Jovens e Adultos - EJA, procedentes de bairros e fazendas da cidade de Palmeiras de Goiás. Após a exibição do recurso áudio-visual foi realizado um debate com os estudantes sobre o tema. A avaliação da proposta pedagógica foi realizada de forma qualitativa por meio de observações in loco e quantitativa por meio de dados coletados com questionários. A proposta pedagógica realizada com o vídeo mostrou ser uma metodologia educacional favorável para a execução de propostas de EA, uma vez que motivou os estudantes para os processos educativos, permitiu boa interação entre professores e estudantes, possibilitando a construção significativa de novos conhecimentos sobre a problemática dos agrotóxicos, além de sensibilizar os estudantes para essa problemática ambiental. Dessa forma, os resultados positivos encontrados justificam a importância do uso de metodologias diferenciadas no ensino, pois as mesmas são atrativas, estimulam o processo reflexivo e crítico dos estudantes, proporcionando mudanças de atitudes diante da problemática dos agrotóxicos.
\end{abstract}

Palavras chave: Educação Ambiental, Problemática dos agrotóxicos, Vídeos, Sensibilização, EJA.

\begin{abstract}
Environmental Education (EE) aims sensitize all citizens to environmental problems and the preservation of the environment.In this sense, the present study aimed develop, implement and evaluate the effectiveness of the video entitled "Environmental Education: building knowledge about the problem of pesticides" as educational technology to discuss the indiscriminate use of pesticides and its consequences the human and the environment. The video was prepared by the teacher and displayed for the students of 4th year high school Education Youth and Adults coming from neighborhoods and farms in the city of Palmeiras de Goiás. After viewing the video was developed a discussion with students about the theme. The evaluation of the educational proposal was performed qualitatively through on-site observations and quantitatively by data collected by the questionnaires. The pedagogical proposal performed with the
\end{abstract}


video proved to be a favorable educational methodology for performing the proposals EA once that motivated students to educational processes, allowed good interaction between teachers and students, enabling significant construction of new knowledge on the issue of pesticides, addition to sensitize students to this environmental problem. Thus, the positive results justify the importance of using different methodologies in teaching, because they are attractive, stimulate reflective and critical process students, providing changes in attitudes in relation of pesticides problematic.

Key-words: Environmental education, pesticides problems, videos, sensitization, EJA.

\section{1 - INTRODUÇÃO}

É fundamental entender o que é a Educação Ambiental (EA). Para tanto, a Lei Federal $n^{\circ}$. 9.795/99, Art. $1^{\circ}$ (Política Nacional de Educação Ambiental - PNEA, BRASIL ,1999) define a EA como "os processos por meio dos quais o indivíduo e a coletividade constroem valores sociais, conhecimentos, hábitos, atitudes e competências voltados para a conservação do meio ambiente [...]”. Dessa forma, a EA propõe discutir os problemas ambientais e disseminar conhecimentos por meio da sensibilização e conscientização da relevância da preservação do meio ambiente. Nesse sentido, a EA pressupõe ações educativas que sejam permanentes e que abordem as várias problemáticas ambientais da atualidade (NARCIZO, 2009).

Dentre os vários problemas ambientais, é notório que o consumo de agrotóxicos vem tomando proporções cada vez maiores e que sua utilização em larga escala é responsável por um grande número de contaminações e doenças de trabalhadores das lavouras, além das consequências ao meio ambiente e do agravo nas condições de saúde da população que consome alimentos contaminados, como confirma Sacconi (2001, p. 285), “o uso indiscriminado de defensivos é danoso para a lavoura e para a saúde humana". Para tanto, é relevante saber o que é agrotóxico, Reis (2008, p. 135) define agrotóxicos como: “Os agrotóxicos podem ser definidos como quaisquer produtos de natureza biológica, física ou química que tem a finalidade de exterminar pragas" [...]. Diante desta conjuntura, o uso indiscriminado de agrotóxicos gera vários danos ao meio ambiente. Estes problemas ambientais relacionados aos agrotóxicos são encontrados no município da cidade de Palmeiras de Goiás, que é uma região basicamente agrícola. Na busca de soluções, a EA surge para tentar reverter essa situação ou ao menos amenizá-la. De acordo com Pádua e Tabanez (1998, p. 196), a "EA propicia o aumento de conhecimentos, mudança de valores e aperfeiçoamento de habilidades, condições básicas para estimular maior integração e harmonia dos indivíduos com o meio ambiente". 
Um dos caminhos para iniciar a construção do conhecimento sobre a problemática do uso de agrotóxicos é por meio propostas de EA na escola, local onde as crianças, jovens, adultos, podem ser sensibilizados diariamente nas aulas. Dias (1992, p. 4) enfatiza que "a maioria dos nossos problemas ambientais têm suas raízes em fatores socioeconômicos, políticos e culturais, e que não podem ser previstos ou resolvidos por meios puramente tecnológicos". Diante disso, percebe-se a relevância da conscientização dos alunos por meio da EA trabalhada nas escolas, visando a construir cidadãos com responsabilidade.

Transcender ao conhecimento não é tarefa fácil, pois as crianças e jovens vivenciam e participam a cada dia dos avanços nas tecnologias. Nesse sentido as tecnologias também devem ser inseridas nos processos educativos, pois como afirma Moran (2007, p. 164) "as tecnologias são pontes que abrem a sala de aula para o mundo". Para tanto, é importante a escola fazer uso das tecnologias para sensibilizar os alunos sobre a importância da preservação ambiental. Uma estratégia interessante é o uso do vídeo em sala de aula, pois como ressalta Férres (1996, p. 9) "a força da linguagem audiovisual consegue dizer muito mais do que captamos, e encontra dentro de nós uma repercussão em imagens básicas, centrais, simbólicas, arquetípicas, com as quais nos identificamos". É fundamental que as escolas proporcionem uma base educativa em EA para seus alunos, e o elemento central é o planejamento educativo, e o uso de estratégias com ampla utilização de recursos tecnológicos. É nesse aspecto, nas estratégias, que é primordial valorizar os vídeos educativos, pois como afirma Moran (1995) os vídeos auxiliam no desenvolvimento do senso crítico e na construção do conhecimento coletivo.

Nesta iniciativa, a de entrelaçar a EA à tecnologia audiovisual, cria-se possibilidades para uma nova construção de conhecimento em relação à problemática do uso indiscriminado dos agrotóxicos. Dentro desse processo, busca-se a sensibilização em relação ao meio ambiente e sua preservação. Nesse sentido, esclarece Tozoni-Reis (2007, p. 197) quando afirma que "a educação no sentido da pedagogia crítica, tem como preocupação central a prática social transformadora, a construção de relações sociais plenas de humanidade dirigidas para a sustentabilidade social e ambiental".

Assim, o presente trabalho visou desenvolver uma proposta pedagógica em EA por meio da elaboração, aplicação e avaliação em sala de aula do vídeo intitulado "Educação Ambiental: construindo conhecimentos sobre a problemática dos agrotóxicos", com o intuito de expor por meio do vídeo a problemática inerente aos 
agrotóxicos, bem como ampliar a consciência ambiental dos alunos do $4^{\circ}$ Ano do Ensino Médio de Educação de Jovens e Adultos (EJA).

\section{2 - OBJETIVOS}

\section{A - GERAL}

- Elaborar, aplicar em sala de aula e avaliar a eficácia do vídeo "Educação Ambiental: construindo conhecimentos sobre a problemática dos agrotóxicos" em proposta de EA.

\section{B - ESPECÍFICOS}

- Abordar a EA de forma motivadora;

- Favorecer a construção de novos conhecimentos pelos estudantes acerca da problemática dos agrotóxicos;

- Discutir esse problema ambiental com os estudantes de forma crítica e reflexiva;

- Sensibilizar os estudantes para o problema ambiental em análise.

\section{3 - METODOLOGIA}

\section{A - PÚBLICO-ALVO}

O público alvo desta pesquisa foram 25 estudantes do $4^{\circ}$ Ano do Ensino Médio, da Educação de Jovens e Adultos. A faixa etária dos alunos foi bastante heterogênea, com estudantes de 20 anos até 50 anos de idade, de ambos os sexos. Todos os estudantes aceitaram participar da pesquisa ao assinar o Termo de Consentimento Livre e Esclarecido.

\section{B - APRESENTAÇÃO DO RECURSO DIDÁTICO}

O vídeo intitulado "Educação Ambiental: construindo conhecimentos sobre a problemática dos agrotóxicos"1 foi elaborado por meio do programa editor de vídeos Windows MovieMaker®, instalado no sistema operacional Windows XP®. Este vídeo possui cerca de sete minutos e quarenta e três segundos de duração, foi elaborado com imagens e textos, e aborda de forma crítica e reflexiva conteúdos relacionados ao uso de agrotóxicos na agricultura. O vídeo explica o que são os agrotóxicos, como eles surgiram, quais os interesses do governo ao incentivar o uso desses produtos, apresenta

\footnotetext{
${ }^{1} \mathrm{O}$ vídeo foi disponibilizado no site do You Tube: http://www.youtube.com/watch?v=b_wRukc3CKY
} 
os vários problemas em torno do uso de agrotóxicos e os caminhos para minimizar os danos causados por esses produtos.

O vídeo explica que os agrotóxicos são substâncias tóxicas que podem gerar graves prejuízos à saúde humana e inúmeras pessoas estão expostas a esses produtos: trabalhadores das indústrias que fabricam os produtos, trabalhadores de transporte e comércio, trabalhadores agrícolas e, inclusive, a população em geral que consome alimentos contaminados, como afirma Sassine (2009, p. 3-4) [...] "Os alimentos que chegam hoje à mesa do consumidor goiano estão mais contaminados do que há sete anos. [...] No campo, nunca houve tantos casos de intoxicação de trabalhadores rurais como agora, mesmo com a diminuição acelerada da mão-de-obra rural" [...].

Então, o vídeo apresenta caminhos para minimizar os danos causados pelos agrotóxicos. As pessoas podem, por exemplo, consumir, preferencialmente, alimentos orgânicos, produzidos sem agrotóxicos. O recurso áudio-visual discute que os trabalhadores agrícolas são muito susceptíveis à contaminação por agrotóxicos, pois manipulam os produtos, e ressalta a importância do uso de Equipamentos de Proteção Individual (EPIs) para reduzir os riscos de contaminação. A contaminação do meio ambiente pelos agrotóxicos pode, também, ser reduzida com a formação de trabalhadores agrícolas conscientes, e que tenham a preocupação em armazenar e aplicar os produtos corretamente. Além disso, os trabalhadores precisam fazer o descarte de embalagens e a lavagem de equipamentos contaminados por agrotóxicos de forma segura. O vídeo mostra atitudes erradas, ações corretas e frases realistas, que podem mudar a realidade e minimizar os danos causados pelos agrotóxicos, como expõe a Figura 1. 
Figura 1 - Cenas do vídeo “Educação Ambiental: construindo conhecimentos sobre a problemática dos agrotóxicos".

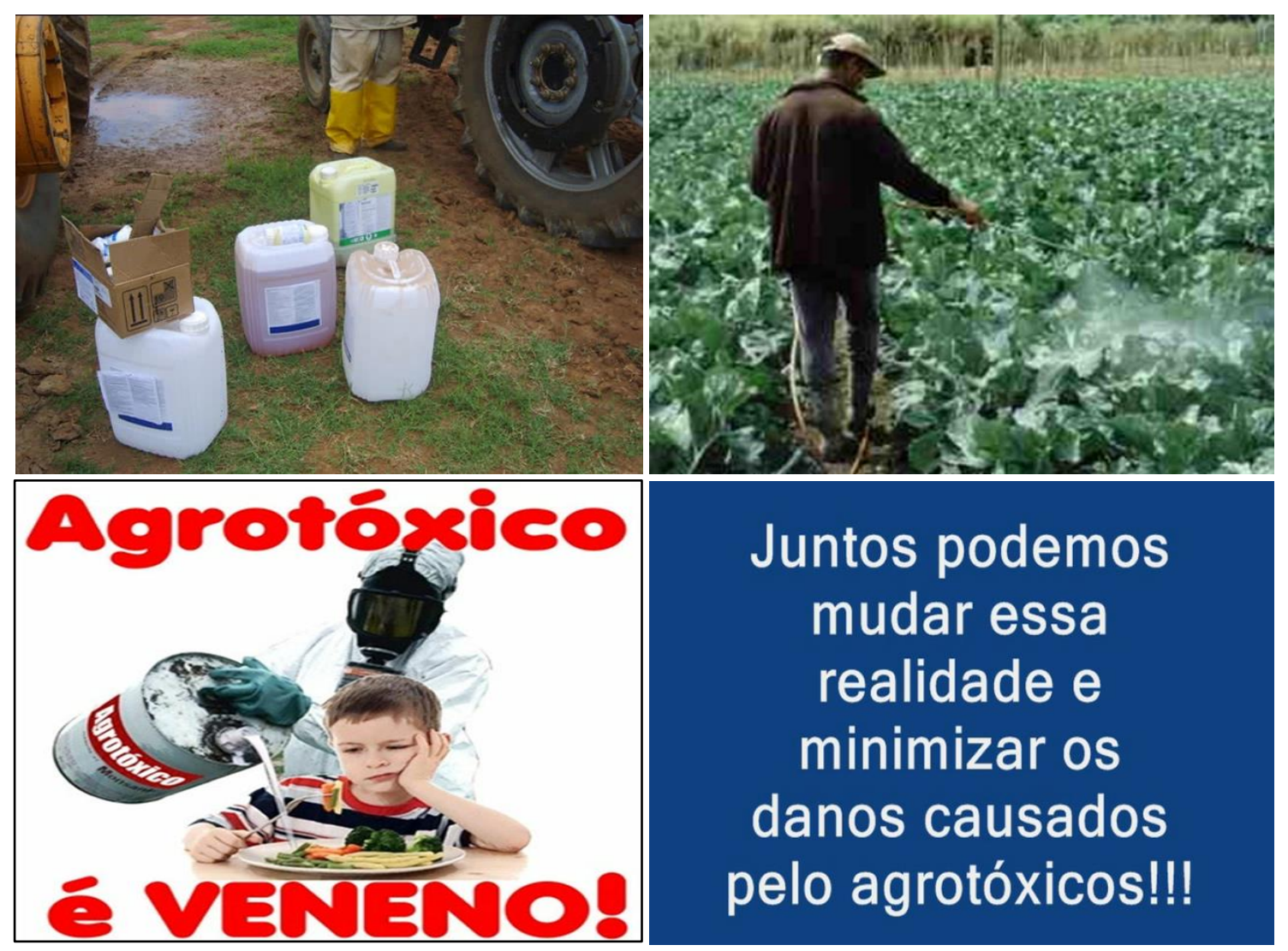

Fonte: http://www.youtube.com/watch?v=b_wRukc3CKY. Imagens disponibilizadas publicamente.

\section{C - DESENVOLVIMENTO DAS ATIVIDADES EDUCATIVAS}

Inicialmente, foi aplicado um questionário pré-teste visando a avaliar os conhecimentos e concepções prévias dos estudantes acerca da problemática dos agrotóxicos. Em seguida, foi apresentado ao $4^{\circ}$ ano do Ensino Médio da Educação de Jovens e Adultos - (EJA), o vídeo intitulado "Educação Ambiental: construindo conhecimentos sobre a problemática dos agrotóxicos”. Após a exibição do vídeo foi realizado um debate com o intuito de discutir conceitos e refletir sobre a problemática apresentada. O debate foi mediado pela professora que teve sempre a preocupação de problematizar e contextualizar sobre o tema. Ao final das atividades foi aplicado um 
questionário pós-teste com o objetivo de avaliar se o vídeo conseguiu sensibilizar os estudantes para a problemática e levá-los a construir novos conhecimentos sobre o tema.

Esta proposta pedagógica foi desenvolvida em três aulas de 50 minutos. Inicialmente, foi feita uma visita à escola, o primeiro contado com a diretora e coordenadora, e um breve diálogo com a turma acerca do projeto. As três aulas programadas para a pesquisa foram distribuídas durante a semana, com intervalos de apenas um dia entre elas. $\mathrm{Na}$ primeira aula foi aplicado o questionário pré-teste. $\mathrm{Na}$ segunda aula foi exibido o vídeo "Educação Ambiental: construindo conhecimentos sobre a problemática dos agrotóxicos" por duas vezes, e o debate. E na terceira aula foi aplicado o questionário pós-teste.

\section{D - AVALIAÇÃ̃O}

A avaliação da proposta pedagógica foi realizada qualitativa e quantitativamente. A análise qualitativa foi feita por meio de observações e registros das falas e comportamentos dos estudantes no decorrer das atividades educativas. A análise quantitativa foi realizada com base nos dados coletados nos questionários pré-teste e pós-teste. Foram aplicados em sala de aula questionários com questões objetivas e discursivas, sendo dez questões acerca do conteúdo em estudo, que terão por objetivo investigar as percepções dos estudantes acerca da problemática dos agrotóxicos antes e após a exibição do vídeo, e três questões acerca da proposta pedagógica com uso do vídeo, visando avaliar a satisfação dos estudantes em participar de aulas com tecnologias educacionais (Tabela 1). As três últimas questões foram inseridas apenas no questionário pós-teste. As questões acerca do conteúdo em estudos foram analisadas segundo um roteiro de respostas esperadas.

Tabela 1 - Questões dos questionários usadas para avaliação da proposta pedagógica.

\begin{tabular}{cc}
\hline $\begin{array}{c}\mathbf{N}^{\circ} \text { das } \\
\text { questões }\end{array}$ & Questão \\
\hline 1 & O que são os agrotóxicos? \\
2 & $\begin{array}{r}\text { Desde a antiguidade o homem modifica a natureza em busca de espaço e alimento. Como essa } \\
\text { transformação contribuiu para o uso intenso dos agrotóxicos? }\end{array}$ \\
3 & O Brasil é o maior consumidor de agrotóxicos do mundo. Nesse sentido, qual o interesse do \\
& governo em incentivar o uso de agrotóxicos? \\
5 & Cite alguns incentivos do governo para a maximização do uso de agrotóxicos. \\
6 & Cite ações corretas por parte dos trabalhadores agrícolas para proteção pessoal contra a \\
& contaminação por agrotóxicos.
\end{tabular}




\begin{tabular}{|c|c|}
\hline 7 & $\begin{array}{l}\text { Cite ações corretas por parte dos trabalhadores agrícolas para proteção do meio ambiente } \\
\text { contra a contaminação por agrotóxicos }\end{array}$ \\
\hline 8 & $\begin{array}{c}\text { Cite ações corretas por parte da população em geral para minimizar danos à saúde causados } \\
\text { por agrotóxicos. }\end{array}$ \\
\hline 9 & Cite alguns tipos de equipamentos de proteção individual (EPIs). \\
\hline 10 & O que é a Educação Ambiental e quais os seus objetivos? \\
\hline 11 & $\begin{array}{l}\text { Você considera que assistir ao vídeo conseguira judá-lo a aprender acerca da problemática dos } \\
\text { agrotóxicos? ( ) Sim ( ) Não Por que? }\end{array}$ \\
\hline 12 & $\begin{array}{l}\text { Você considera que as tecnologias midiáticas garantem maior atratividade no contexto de } \\
\text { ensino-aprendizagem, tornando as aulas mais dinâmicas e interessantes?( ) Sim ( ) Não } \\
\text { Por que? }\end{array}$ \\
\hline 13 & $\begin{array}{l}\text { Você considera que o vídeo conseguiu sensibilizá-lo para a problemática dos agrotóxicos? } \\
\text { Você pretende colocar em prática tudo que aprendeu? ( ) Sim ( ) Não Por que? }\end{array}$ \\
\hline
\end{tabular}

Os dados coletados com as dez primeiras questões do questionário acerca dos conteúdos relacionados à problemática dos agrotóxicos foram analisadas por meio do teste estatístico não paramétrico McNemar. O objetivo desse teste estatístico foi verificar se a proposta pedagógica desenvolvida com o vídeo favoreceu a construção significativa de conhecimentos acerca dos conteúdos em estudo. A hipótese nula (H0) considerou que a proposta pedagógica não favoreceu a construção de conhecimentos e a hipótese alternativa (H1) considerou que as proposta pedagógica favoreceu a construção de conhecimentos. Assumindo que o valor critico de qui-quadrado $\left(\mathrm{X}^{2}\right)$ para grau de liberdade 1 e alfa $5 \%$ é $3.84, X^{2}<3.84$ aceita-se $H 0$ e de $X^{2}>3.84$ rejeita-se H0. Dessa forma, a análise estatística possibilitou verificar se o uso do vídeo em sala de aula favoreceu o processo de ensino aprendizagem, a construção de novos conhecimentos e a sensibilização dos estudantes para a problemática dos agrotóxicos. As três últimas questões do questionário que visavam a avaliar a satisfação dos estudantes em participar da atividade com o vídeo foram analisadas de forma percentual.

\section{4 - RESULTADOS}

As atividades da presente pesquisa tiveram início com a avaliação dos conhecimentos prévios dos estudantes por meio do questionário pré-teste. Inicialmente a professora fez uma introdução do objetivo da atividade, do assunto em pauta e entregou os questionários para todos os participantes. Os alunos fizeram uma leitura das questões, começaram a responder, e não demonstraram dificuldades quanto ao teor das questões, somente alguns não sabiam o significado de algumas palavras, e estas foram explicadas pela professora. Nesse momento inicial foi possível perceber que os estudantes tinham conhecimentos prévios sobre os agrotóxicos, mas não conseguiam 
identificar claramente a problemática envolvendo os agrotóxicos. De acordo com os comentários dos alunos do $4^{\circ}$. Ano do Ensino Médio da EJA, eles sabiam que os agrotóxicos são necessários para as lavouras, mas não davam muita atenção para as problemáticas envolvidas. Dessa forma, logo após a avaliação inicial foi aplicado o vídeo para todos com o objetivo de favorecer a construção de novos conhecimentos sobre o assunto.

A professora exibiu o vídeo "Educação Ambiental: construindo conhecimentos sobre a problemática dos agrotóxicos" para a turma duas vezes. A reação dos estudantes ao uso do vídeo em sala de aula foi muito positiva, uma vez que ficaram muito empolgados e interessados em participarem do momento de apresentação do recurso audiovisual. A participação foi excelente, pois todos comportaram de forma a notar que estavam gostando, e nenhum aluno ausentou-se da sala de aula de vídeo neste momento.

Após a exibição do vídeo foi realizado um debate com a turma para discussão da problemática dos agrotóxicos. No desenvolver das atividades a interação foi ótima, pois acontecia a todo o momento um diálogo entre a professora e os estudantes. Os conteúdos foram apresentados por meio de contextualização e problematização. A participação dos alunos durante o debate foi ativa, pois os mesmos demonstraram atenção durante a explicação da professora, e quando tinham dúvidas faziam perguntas sem timidez. O debate após o vídeo foi satisfatório e favoreceu a construção de novos conhecimentos, pois muitos alunos comentaram que antes não sabiam sobre o alto uso de agrotóxicos no Brasil, e nem como ocorreu historicamente o surgimento das pragas, entre outros pontos. Durante o debate um momento que chamou a atenção, foi quando um aluno que era trabalhador rural se manifestou dizendo que fazia uso de agrotóxicos em hortas sem nenhuma proteção, e que o vídeo o fez perceber o quanto é importante o uso dos EPIs.

Após o debate foi aplicado o questionário pós-teste. Os estudantes responderam plenamenteas questões pós-teste, e após verificação das respostas, notouse claramente que o vídeo contribui de forma positiva, pois os estudantes elaboraram respostas com coerência, comprovando que conseguiram construir novos conhecimentos sobre o assunto proposto, e até mesmo rever seus conceitos sobre agrotóxico. Após as atividades com o vídeo alguns estudantes conceituaram agrotóxicos como: 
"São substâncias conhecidas como venenos químicos usados para combater as pragas que infestam as lavouras".

"Agrotóxicos são produtos químicos que servem para controlar e matar os insetos nas lavouras".

"Os agrotóxicos são venenos que os agricultores pulverizam suas plantações para tentar acabar com as pragas".

Com o vídeo os estudantes perceberam que o uso de agrotóxicos tornou-se necessário historicamente porque o homem modifica a natureza em busca de espaço e alimento. Nesse sentido, os estudantes explicaram que:

"Desde os tempos mais remotos, a população vem aumentando, assim surge à necessidade de aumentar as moradias e a produção de alimentos, e para isso, o homem passou a destruir a natureza por causa da agricultura, e com isso destruir também as moradias dos insetos. Para combater o aumento dos insetos é necessário usar agrotóxicos".

"As pessoas procuram lugares férteis, e que sejam espaçosos, para isso tiverem que modificar a natureza, como derrubar várias árvores para plantar, e esse modificar afetou os seres vivos que se tornaram pragas, aumentaram ao ponto de invadir as lavouras. Por isso é necessário os agrotóxicos".

Com o vídeo foi possível discutir, também, que o Brasil é maior consumidor de agrotóxicos do mundo, e que é interesse do governo incentivar o uso de agrotóxicos (TAVELLA et al, 2011; LONDRES, 2011). Ao serem questionados sobre esse assunto os estudantes mostraram perceber esse contexto e responderam que:

"As pessoas que fazem parte do governo incentiva os agricultores a usarem a cada ano mais agrotóxicos em suas lavouras para que a economia do nosso país cresça, aumentando os lucros".

"O interesse do governo em estimular o uso cada vez maior dos agrotóxicos nas lavouras tem por objetivo fortalecer a economia através do agronegócio".

"O governo oferece para aos produtores empréstimos para que ele produza em maior quantidade, assim aumentando também a quantidade de agrotóxicos".

"A verdade é que em nosso país para a área da agricultura existem isenções fiscais, tributárias, e pouca fiscalização em relação aos agrotóxicos, tornando o uso muito maior".

Sem dúvida, o uso dos agrotóxicos nas lavouras tem sido positivo, pois elevou a economia do Brasil a um patamar jamais visto e, consequentemente gerou grandes lucros (PERES \& MOREIRA, 2007). Mas também, tem o aspecto negativo, que são os problemas ambientais oriundos do uso indiscriminado dos agrotóxicos, como a contaminação dos alimentos, dos lençóis freáticos, entre outros.

Após a exibição do vídeo "Educação Ambiental: construindo novos conhecimentos sobre a Problemática dos Agrotóxicos", os próprios estudantes 
expuseram alguns problemas ambientais que conheciam como a morte da maioria dos peixes dos Rios dos Bois no município de Palmeiras de Goiás, óbito de um trabalhador rural da cidade com comprovação médica de intoxicação por agrotóxicos e a contaminação de alimentos, entre eles o tomate. Nesse sentido, a atividade conseguiu alertar os estudantes para os problemas ambientais. Após a atividade com recurso audiovisual alguns estudantes responderam:

"Problemas com o uso de agrotóxicos nas lavouras são grandes e sérios, pois contamina as pessoas que trabalham com esses produtos, podendo causar danos a saúde".

"Assistindo o vídeo aprendi que a contaminação para as pessoas que trabalham com os agrotóxicos podem ser agudas como hemorragias, e crônico, como até câncer".

"Um dos problemas graves em relação ao uso de agrotóxicos nas lavouras são os riscos de contaminar o meio ambiente, como os rios, matando os peixes".

As atividades realizadas com o vídeo capacitaram os estudantes a perceber os problemas ambientais gerados pelos agrotóxicos e os sensibilizaram para a compreensão de ações corretas que minimizem os problemas gerados pelo uso abusivo desses produtos químicos. Durante as atividades, todos os estudantes manifestaram verbalmente e no questionário pós-teste a preocupação com o assunto abordado. Nesse sentido, alguns alunos afirmaram que:

"São várias classes de pessoas que tem contato com agrotóxicos, como quem fabrica, quem compra, o trabalhador rural que maneja o veneno, e também a pessoa que come os alimentos contaminados, cada qual deverá fazer sua parte para diminuir os danos".

"Nossa saúde e o meio ambiente merecem ser bem tratados, respeitados, por isso devemos ser conscientes que os alimentos produzidos sem agrotóxicos, os chamados orgânicos, preservam nossa vida, e o meio ambiente, o solo e a água".

"As embalagens que trazem os agrotóxicos também estão contaminadas. Se o trabalhador rural for fazer a lavagem dessas embalagens não devem reutilizar a água do enxágue, essa é uma atitude correta".

Dessa forma, o vídeo conseguiu sensibilizar os estudantes para a problemática dos agrotóxicos, o que é muito importante devido às características socioeconômicas locais. A cidade de Palmeiras de Goiás tem sua economia em grande parte voltada para a agricultura, e, assim, necessita de trabalhadores rurais.

O colégio da rede estadual da cidade tem em sua modalidade de ensino a Educação de Jovens e Adultos, onde muitos estudantes trabalham nas lavouras, o que pode ser observado na turma em que as atividades foram desenvolvidas. Após o vídeo 


\title{
Ensino, Saúde e Ambiente - V7 (2), p. 28-45, Ago. 2014
}

os estudantes, muitos dos quais já atuavam como trabalhadores rurais, compreenderam que usar Equipamentos de Proteção Individual (EPIs) pode salvar suas vidas quando estão em contato com os agrotóxicos. Como supracitado, inclusive um dos estudantes comentou que não fazia uso de nenhuma proteção, e que depois que assistiu ao vídeo percebeu a necessidade de se proteger, usando luvas, máscaras, roupas adequadas, óculos e outros. Os estudantes expressaram preocupação em usar EPIs após as atividades com o vídeo:

\begin{abstract}
"Quando se lida com veneno, que são os agrotóxicos, todo cuidado é pouco, mas é muito importante que a pessoa que esteja em contato com esse veneno esteja usando roupas que cobrem o corpo para não acontecer intoxicação".

"É importante para quem trabalha em contato com os agrotóxicos usar o equipamento de proteção. No vídeo mostrou os óculos para proteger os olhos e até mesmo capacete para amparar o couro cabeludo de ser contaminado".

"Uma proteção que não deve deixar deser usada pelo trabalhador rural é a máscara para prevenir que o veneno chegue ao nariz, porque se não, com certeza a pessoa vai ficar respirando aquele agrotóxico por horas, podendo ser contaminado e ficar doente seriamente".
\end{abstract}

O vídeo conseguiu sensibilizar os estudantes para a problemática em estudo e favorecer a construção de novos conhecimentos. A análise quantitativa dos acertos dos estudantes às questões nos questionários pré-teste e pós-teste permitiu verificar que os mesmos construíram respostas mais abrangentes e elaboradas após as atividades, o que indica que compreenderam de forma significativa o tema. Assim, o número de estudantes que acertaram cada questão após as atividades com o recurso audiovisual foi maior do que o número de estudantes que acertaram antes das atividades, o que permite inferir que o vídeo favoreceu a construção de novos conhecimentos sobre a problemática dos agrotóxicos (Gráfico 1). 


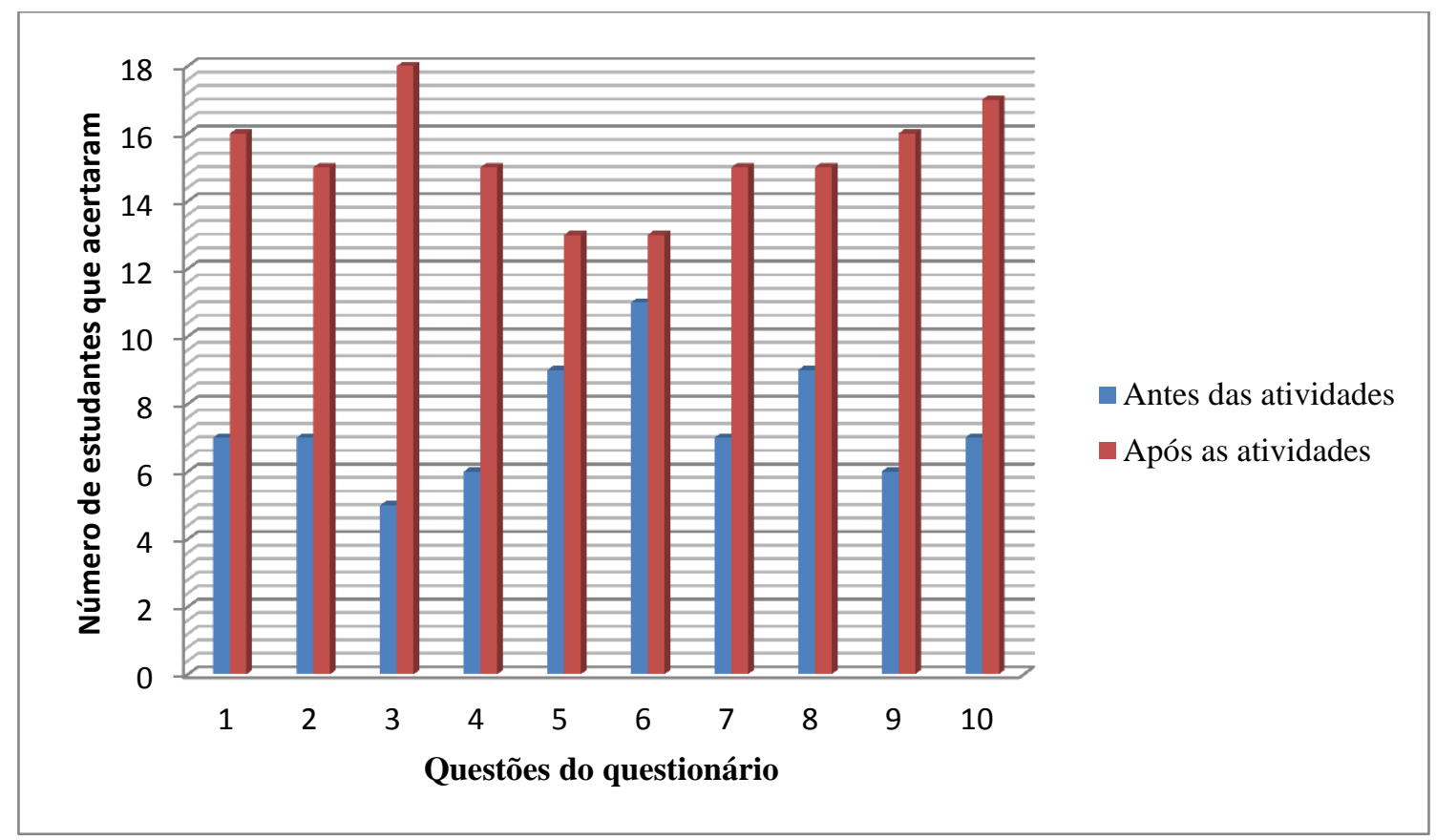

Figura 2 - Número total de estudantes que responderam corretamente às questões dos questionários (Numeração conforme tabela 1) antes e após o desenvolvimento das atividades com o vídeo.

Os resultados da análise estatística permitiram confirmar que o vídeo foi realmente eficaz para facilitar a construção de novos e corretos conhecimentos por parte dos estudantes sobre a problemática dos agrotóxicos (Tabela 2).

Tabela 2 - Valores de Qui-Quadrado $\left(\mathrm{x}^{2}\right)$ e $\mathrm{p}$ gerados pelo teste de McNemar para cada questão do questionário (Numeração conforme tabela 1).

\begin{tabular}{ccc}
\hline Questão do Questionário & Valor de Qui-Quadrado & Valor de p \\
\hline 1 & 6.05 & 0.013 \\
2 & 10.56 & 0.001 \\
3 & 13.47 & 0.0002 \\
4 & 8.47 & 0.003 \\
5 & 4.92 & 0.026 \\
6 & 5.88 & 0.015 \\
7 & 10.56 & 0.001 \\
8 & 8.47 & 0.003 \\
9 & 8.45 & 0.003 \\
10 & 10.31 & 0.001 \\
\hline
\end{tabular}

Os resultados da avaliação da metodologia desenvolvida com vídeo, avaliadas com as questões de 11 a 13 do questionário, também podem ser considerados positivos. Quando questionados se o vídeo conseguiu ajudá-los a aprender sobre a problemática dos agrotóxicos, todos os estudantes responderam "sim". Além disso, todos os estudantes responderam também que as tecnologias vieram para acrescentar em seus estudos, gerando maior atratividade, dinâmica, e interesse nas atividades em sala de aula. Quando os estudantes foram questionados se o vídeo conseguiu sensibilizá-los e se 


\section{Ensino, Saúde e Ambiente - V7 (2), p. 28-45, Ago. 2014}

os mesmos pretendem colocar em prática o que aprenderam, os resultados foram ótimos, pois todos demonstraram em suas respostas que após o vídeo e os novos conhecimentos construídos pretendem socializar o que aprenderam, e os que trabalham nas lavouras colocar em prática as ações corretas.

\section{5 - DISCUSSÃO}

O presente trabalho teve início com a avaliação do conhecimento prévio dos estudantes a respeito da problemática dos agrotóxicos. Antunes \& Sabóia (2010) afirmam que os conhecimentos prévios são resultado de experiências de vida, e geralmente consiste em ideias superficiais e não sistemáticas. Conhecer o que os estudantes já sabem sobre o conteúdo permite propor metodologias de ensino que desafiem os conhecimentos iniciais, e que levem os estudantes à construção e reconstrução conhecimentos (MORTIMER, 1999). Sendo assim, o processo de ensinoaprendizagem nunca começa do zero, nem mesmo nos momentos iniciais da vida escolar, ou seja, é um processo que envolve diversas etapas, nas quais os conhecimentos, as ideias e as opiniões dos alunos vão sendo gradativamente ampliadas e reformuladas.

Após a avaliação dos conhecimentos prévios sobre a problemática dos agrotóxicos e o estabelecimento do ponto de partida para o processo de ensino aprendizagem, foi desenvolvida uma proposta pedagógica com uso de tecnologia educacional audiovisual. O uso de metodologias diferenciadas em sala de aula é importante porque a educação vem passando por um momento de grandes transformações e avanços tecnológicos. Assim, surge a necessidade de uma contínua atualização em relação ao uso das tecnologias na escola. Rosa (2000, p. 33-49) ressalta a importância da realização de aulas diferenciadas ao afirmar que "atividades diferentes das desenvolvidas no cotidiano estimulam os alunos para as práticas educativas". Nesse sentido é preciso romper com as práticas pedagógicas tradicionais e inserir em sala de aula recursos educacionais diversificados.

As aulas tradicionais, que usam como recursossomente o quadro, o giz e os livros didáticos, já não vêm proporcionando aos alunos muito interesse pelos processos educativos, e se tornam muitas vezes, até cansativas, além de fazer com que os estudantes sejam meramente passivos, ou seja, apenas ouvintes. Nessa visão, o professor atua como o detentor do conhecimento e somente explica, expõe e impõe os conteúdos. No entanto, as novas tendências educacionais vêm rompendo com esse 
modelo de educação e estabelecendo formas diferentes de ensinar e aprender, onde o professor é o mediador do processo de ensino aprendizagem e o aluno é ativo na construção do próprio conhecimento. Desta forma, o uso de tecnologias em sala de aula torna as atividades mais agradáveis e interessantes e cria um ambiente onde educador e educando aprendem juntos numa troca simultânea de saberes (RIBEIRO, 2006, p.135).

Nesse estudo foi usado como tecnologia educacional o vídeo intitulado "Educação Ambiental: construindo conhecimentos sobre a problemática dos agrotóxicos" e as atividades foram conduzidas de forma a estimular a participação dos estudantes e torná-los ativos na construção de novos conhecimentos. O uso do vídeo como metodologia diferenciada conseguiu gerar motivação e prender a atenção dos estudantes para o assunto em análise. Esse resultado pode ser justificado por Antunes, Dutra e Oliveira (2010), quando afirmam que o interesse do estudante é maior quando atividades incomuns são aplicadas, trazendo novo ânimo para a análise da teoria ministrada.

O vídeo educativo vem se tornando uma tecnologia encontrada em muitas escolas brasileiras sendo caracterizado como recurso educativo. Nota-se uma grande aceitação dos estudantes no uso dos vídeos em sala de aula, pois o som combinado com as imagens torna o conteúdo impactante. Mas Oliveira, Correia e Genovese (2010, p. 11) ressaltam que "o vídeo se insere como ferramenta motivadora e não como instrumento que refaz uma aula teórica na televisão". Nesse sentido, Moran (1995) acrescenta que o "uso do vídeo em sala de aula é importante para introduzir um novo assunto e despertar o interesse dos estudantes para o tema".

$\mathrm{O}$ vídeo pode ser usado em sala de aula para trabalhar inúmeros temas, e diversos estudos vêm caracterizando os vídeos como metodologias eficazes para trabalhar a EA. De acordo com Antunes, Dutra e Oliveira (2010) os vídeos contribuem para facilitar acompreensão dos estudantes acerca das problemáticas ambientais e direciona discussões na busca de soluções para os problemas atuais. Na literatura existem vários trabalhos que apresentam propostas pedagógicas diferenciadas e que associam tecnologias educacionais e Educação Ambiental. O trabalho de Antunes \& Sabóia (2010) intitulado "Projeto Tela Verde: A Problemática do Lixo Abordada por Meio de Recursos Audiovisuais", teve por objetivo abordar primordialmente a problemática do lixo numa proposta de Educação Ambiental por meio de documentários, e os resultados foram significativamente positivos quanto às questões ambientais. Outro trabalho relevante é Oliveira et al (2010) intitulado "Conhecer para 
preservar: o Documentário como Projeto de Intervenção Escolar”, que teve como objetivo promover experiências de aprendizagem quanto à EA e Patrimonial, e incentivou o uso das tecnologias no Ensino Médio.

Dessa forma, o uso do vídeo em sala de aula é considerado positivo em muitos estudos encontrados na literatura. Nesse estudo o vídeo, também, se mostrou eficaz para trabalhar a EA, pois favoreceu a sensibilização e a construção de novos conhecimentos pelos estudantes acerca da problemática dos agrotóxicos. Mas a eficácia dos vídeos como tecnologia educacional depende, em todos os casos, da atuação do professor como mediador das atividades. De acordo com Moran (1995), o vídeo não deve ser inserido em sala de aula como um "tapa buraco" para cobrir problemas inesperados como a falta de um professor, e muito menos usado por professores como "vídeo enrolação" para camuflar aulas sem planejamento. Moran (1995) afirma que o vídeo deve ser inserido em proposta pedagógica em que ele seja integrado ao assunto da aula e discutido. Dessa forma, após a exibição do vídeo, é importante rever as cenas mais importantes e propor caminhos para a análise do recurso audiovisual em classe.

No presente estudo, após a exibição do vídeo, a professora conduziu um debate sobre o assunto, visando aanalisar os conteúdos sobre a problemática dos agrotóxicos. $\mathrm{O}$ debate foi realizado por meio de contextualização e problematização. A contextualização é valorizada por Antunes, Dutra e Oliveira (2010), ao afirmar em que contextualizar consiste em fazer uma relação intrínseca entre os saberes escolares e as questões concretas da vida, o que permite prender de forma mais efetiva a atenção dos estudantes, uma vez que gera significado para os conteúdos curriculares. A problematização, por sua vez, consiste em apresentar os conteúdos na forma de problemas, cujas soluções devem ser elaboradas com base em conhecimentos prévios e nas reflexões sobre o assunto em análise (MADRUGA, 1996). De acordo com Freire (1987, p.70) a problematização favorece a participação ativa dos estudantes nos processos educativos e estimula o pensamento crítico. Contribuindo para a formação de indivíduos pensantes capazes de mudar a sociedade.

A proposta pedagógica realizada com o vídeo mostrou ser uma metodologia educacional favorável para a execução de propostas de EA, uma vez que motivou os estudantes para os processos educativos, permitiu boa interação entre professores e estudantes, possibilitando a construção de novos conhecimentos sobre a problemática dos agrotóxicos, além de sensibilizar os estudantes para essa problemática ambiental. Dessa forma, os resultados positivos encontrados justificam a importância do uso de 
metodologias diferenciadas no ensino. Essa pesquisa foi relevante porque a comprovação da eficácia do vídeo "Educação Ambiental: construindo conhecimentos sobre a problemática dos agrotóxicos" pode caracterizá-lo como positivo em proposta de EA, o que permitirá a sua reprodução e utilização por outros educadores.

\section{6 - CONCLUSÃO}

As atividades realizadas com o vídeo "Educação Ambiental: construindo conhecimentos sobre a problemática dos agrotóxicos" permitiram verificar que esta tecnologia audiovisual foi eficiente em sala de aula visto que oportunizou enormes auxílios na ação pedagógica como um método atrativo e motivador para o processo de ensino-aprendizagem. Ficou perceptível no decorrer do desenvolvimento das atividades, que os estudantes participaram ativamente e desenvolveram reflexões sobre o assunto em questão. A proposta pedagógica favoreceu a construção significativa de novos conhecimentos pelos estudantes sobre o tema em análise. Além disso, detectou-se através das anotações e falas dos estudantes uma sensibilização notável sobre a problemática dos agrotóxicos, uma vez que expressaram a intenção de mudança de atitudes para ações corretas em relação ao uso indiscriminado dos agrotóxicos, bem como a utilização de equipamentos de proteção.

\section{REFERÊNCIAS}

ANTUNES, M. A.; DUTRA, F M.; OLIVEIRA, L. M. Educação Ambiental e novas tecnologias: o uso de vídeos em sala de aula para sensibilização da comunidade escolar. Enciclopédia Biosfera, v.6, n. 10, 2010.

ANTUNES. M. A.; OLIVEIRA, M. L.; SABÓIA, (T. M. S.) Projeto Tela Verde: A problemática do lixo abordada por meio de recurso audiovisuais. Enciclopédia Biosfera, Centro Científico Conhecer - Goiânia, vol.6, n. 9, 2010.

BRASIL. Lei ${ }^{0}:$ 9.795/99, de 27 de abril de 1999. Dispõe sobre a educação ambiental, institui a Política Nacional de Educação Ambiental e dá outras providências. Brasília, 1999.

DIAS, G. F. Educação ambiental: princípios e prática. São Paulo: Gaia, 1992, p. 4.

LONDRES, F. Agrotóxicos no Brasil - Um guia para ação em defesa da vida. Rio de Janeiro: AS-PTA - Assessoria e Serviços a Projetos em Agricultura Alternativa, 2011.

MORTIMER, E. Construindo conhecimento científico em sala de aula. Química Nova na Escola, n. 9, p. 31-40, 1999.

FERRÉS, J. Vídeo e Educação. 2: ed. Porto Alegre: Artes Médicas, 1996, p. 9. 
MADRUGA A. Aprendizagem pela descoberta frente à aprendizagem pela recepção: a teoria da aprendizagem verbal significativa. In: COLL C.; PALÁCIOS J.; MARCHESI A. (orgs). Desenvolvimento psicológico e educação. Porto Alegre: Artes Médicas, p. 68-78, 1996.

MORAN, J. M. O Vídeo na sala de aula. Revista Comunicação \& Educação. v. 2, p. 27-35, 1995.

Análise do vídeo como recurso tecnológico educacional, 2010, 164.

.Desafios da televisão e do vídeo à escola. In:Integração das tecnologias da Educação. Secretaria de Educação à Distância. Brasília: Ministério da Educação, Seed, 2005.

.Desafios na comunicação pessoal. $3^{\text {a. }}$ ed. São Paulo: Paulinas, 2007, p.164.

NARCIZO, K. R. S. Uma análise sobre a importância de trabalhar educação ambiental nas escolas. Rev. Eletrônica Mestr. Educ. Ambient, v. 22, 2009.

OLIVEIRA, M. L.; CORREIA, R. S.; GENOVESE, C. L. C. R. Conhecer para preservar: odocumentário como projeto de intervenção escolar. Enciclopédia Biosfera, v. 6, n. $09,2010$.

PÁDUA, S.; TABANEZ, M. (orgs.). Educação ambiental: caminhos trilhados no Brasil. São Paulo: Ipê. I998, p. 196.

PERES,F.; MOREIRA, J.C. Saúde e ambiente em sua relação com o consumo de agrotóxicos em um pólo agrícola do Estado do Rio de Janeiro, Brasil. Cad. Saúde Pública, Rio de Janeiro, n. 23, 2007.

REIS, J. T. Resumo de Direito Ambiental. Niterói: Impetus, 2008, p. 135.

RIBEIRO, M. L. S. I. O jogo na organização curricular para deficientes mentais. In: KISHIMOTO, T.M. Jogo, brinquedo, brincadeira e a educação. 9. ed. São Paulo: Cortez, Cap. 7, 133 - 141. 2006.

SACCONI, L. A. Dicionário Essencial da Língua Portuguesa. $1^{a}$ Ed. São Paulo: Atual, 2001, p. 50.

SASSINE, J. V. Aumento do uso de agrotóxico, descontrole das contaminações. O Popular. Goiânia, 2009, p. 2-4.

ROSA, P. R. S. O uso dos recursos audiovisuais e o ensino de ciências. Cad. Cat. Ens. Fís., v. 17, n. 1: PP: 33-49, 2000.

TAVELLA, L. B.; SILVA, I. N.; FONTES, L. O.; DIAS, J. R. M; SILVA, M. I. L. O uso de agrotóxicos na agricultura e suas consequências toxicológicas e ambientais.

ACSA - Agropecuária Científica no Semi-Árido, v.07, n.02, 2011.

TOZONI-REIS, M. F. C. Contribuições para uma pedagogia crítica na educação ambiental: reflexões teóricas. In: LOUREIRO, C. F. B (Org.). A questão ambiental no pensamento crítico. Rio de Janeiro: Quartet, v. 1, p. 177-222, 2007. 